\title{
Population-based analysis of curative therapies in stage II non-small cell lung cancer: the role of radiotherapy in medically inoperable patients
}

Sara Moore ${ }^{1,2}$, Bonnie Leung ${ }^{2}$, Jonn $\mathrm{Wu}^{1,3}$ and Cheryl $\mathrm{Ho}^{1,2^{*}}$ (B)

\begin{abstract}
Objectives: Curative intent therapy of stage II NSCLC may include surgical resection or definitive radiotherapy. Primary management with surgery or radiotherapy may be influenced by patient and disease characteristics. We sought to perform a comparison of patients receiving surgery or radical radiation therapy as their curative treatment, and explore the impact of known prognostic factors on outcome.

Materials and methods: A retrospective review was completed of all patients with stage II NSCLC referred to the BC Cancer Agency from 2005 to 2012. Cases were filtered to identify those receiving curative intent therapy including surgery or radiotherapy. Information was collected on known prognostic and predictive factors. The primary outcome measure was overall survival. We compared survival among patients receiving curative intent radiotherapy versus surgical intervention.

Results: A total of 535 patients were referred. Of these, 245 (46\%) received curative intent surgery, 132 (25\%) curative intent radiotherapy, and 158 (30\%) did not receive curative therapy. There were significant differences between cohorts with respect to median age, histology, ECOG PS, smoking status, and weight loss. Median OS was significantly different between cohorts: $61.4 \mathrm{~m}$ surgery, $26.5 \mathrm{~m}$ curative RT, and $13.1 \mathrm{~m}$ non-curative therapy. In a case-matched analysis, median OS remained superior for surgery at $101.6 \mathrm{~m}$ vs $28.1 \mathrm{~m}$ for curative RT. In a multivariate analysis, ECOG PS, weight loss, and treatment cohort all influenced survival. Among patients receiving curative intent radiotherapy, the use of concurrent chemotherapy and RT dose $>=60$ Gy were associated with improved outcomes.
\end{abstract}

Conclusions: Among patients with stage II NSCLC, many are unable to undergo standard of care surgical resection. Radiotherapy provides an inferior yet still curative option in the management of inoperable patients. Further work is needed to optimize outcomes in this population.

Keywords: Non-small cell lung cancer, Stage II, Inoperable, Real-world, Outcomes

\footnotetext{
* Correspondence: cho@bccancer.bc.ca

${ }^{1}$ University of British Columbia, Vancouver, BC V6T 1Z4, Canada

2Department of Medical Oncology, BC Cancer 600 W 10th Avenue

Vancouver, Vancouver, BC V5Z 4E6, Canada

Full list of author information is available at the end of the article
}

(c) The Author(s). 2020 Open Access This article is distributed under the terms of the Creative Commons Attribution 4.0 International License (http://creativecommons.org/licenses/by/4.0/), which permits unrestricted use, distribution, and reproduction in any medium, provided you give appropriate credit to the original author(s) and the source, provide a link to the Creative Commons license, and indicate if changes were made. The Creative Commons Public Domain Dedication waiver (http://creativecommons.org/publicdomain/zero/1.0/) applies to the data made available in this article, unless otherwise stated. 


\section{Background}

Non-small cell lung cancer (NSCLC) is the most frequently diagnosed cancer worldwide [1]. Approximately one-third of patients will present with early stage disease [2], and with recent evidence to support lung cancer screening, it is expected this will become a growing patient population [3, 4]. In the American Joint Committee on Cancer (AJCC) 8th edition, stage II NSCLC encompasses patients with T2b/3 N0 and T1/2N1 disease [5]. Despite being amenable to potentially curative therapy, the survival outcomes in stage II NSCLC are mediocre, with a 5 year overall survival (OS) of $53-60 \%$ with clinical staging and 56-65\% with pathologic staging [5].

The standard of care for stage II NSCLC is surgery [6, 7], followed by adjuvant chemotherapy in higher risk patients [8-11]. There are a proportion of patients who are deemed medically inoperable due to comorbidities or refuse surgery [12-16]. For inoperable stage II patients, the optimal treatment is much less certain. Chemoradiation or radical doses of radiotherapy alone remain a curative option, however there is limited evidence to guide this approach, and outcomes are unclear [17-19].

In this study, we examine the landscape of treatment of stage II NSCLC in a real-world population. We sought to explore outcomes in patients treated with curative intent radiotherapy compared to surgery, and clarify the role of radiotherapy in the medically inoperable population.

\section{Methods}

\section{Population}

A retrospective cohort study was performed of all patients with stage II (by AJCC 7th edition) NSCLC who were referred to BC Cancer between January 2005 and December 2012. BC Cancer is a provincial cancer program which serves a population of 4.6 million. Approximately $80 \%$ of patients with lung cancer in the province of British Columbia (BC) are referred to BC Cancer.

Three cohorts were created based on the type of therapy received:

- Curative intent surgery: sub-lobar resection, lobectomy, pneumonectomy +/- adjuvant chemotherapy

- Curative intent radiation (CurRT): Stereotactic body radiation therapy (SBRT) - 48Gy/4fr, 60Gy/8fr, $60 \mathrm{~Gy} / 15 \mathrm{fr}$. Standard external beam radiotherapy $50 \mathrm{~Gy} / 20 \mathrm{fr}, 50 \mathrm{~Gy} / 25 \mathrm{fr}, 55 \mathrm{~Gy} / 20 \mathrm{fr}, 60 \mathrm{~Gy} / 30 \mathrm{fr}, 66 \mathrm{~Gy} /$ $33 \mathrm{fr}+/$ - concurrent/sequential chemotherapy

- Non-curative therapy: systemic therapy, radiotherapy with palliative intent, or best supportive care

Patients who had another malignancy diagnosed within 5 years prior to lung cancer diagnosis, with the exception of non-melanomatous skin cancer or cervical cancer in situ, were excluded.

\section{Data collection}

Data collection was facilitated by the Outcomes and Surveillance Integration System (OaSIS), a database that houses the Lung Tumor Group outcomes unit. Information was collected through OaSIS on known prognostic factors including: age, sex, smoking history, histology, Eastern Cooperative Oncology Group (ECOG) performance status (PS), and weight loss. Treatment details including chemotherapy, surgery, and radiotherapy were collected retrospectively.

\section{Statistical analysis}

Statistical analysis was conducted using SPSS Version 23. Known prognostic factors were compared between the two cohorts using the Chi-Square test or Fisher's Exact test where appropriate (categorical variables), and the Mann-Whitney test (continuous variables).

The primary outcome measure was overall survival (OS) calculated from the date of diagnosis. Survival curves were compared between cohorts using a log-rank test. A $p$-value of less than or equal to 0.05 was considered statistically significant. Multivariate analysis of potential factors associated with overall survival was performed using the Cox proportional hazards model.

Disease-free survival (DFS) was defined as the date of diagnosis to any recurrence (both local and distant) or death. DFS was compared between patients receiving curative intent surgery or radiotherapy. Recurrence was determined based on imaging and follow-up per treating physician discretion. Patients were censored by date of last follow-up visit at $\mathrm{BC}$ Cancer.

To account for the expected imbalance in prognostic factors between treatment cohorts, a case-matched OS analysis was performed. Patients who received surgery were matched 1:1 with patients receiving curative intent radiotherapy based on age (+/ -5 years), sex, ECOG (0-1 or 2), and smoking status (never, former, current).

An exploratory analysis was performed evaluating the potential effect of radiotherapy dose and the use of chemoradiation on survival. Patients receiving concurrent or sequential chemotherapy were compared to those treated with curative intent RT alone. Patients receiving curative RT were separated into 2 cohorts (> =60Gy, 50-59Gy), and were compared to patients receiving moderate-high dose palliative radiotherapy (30-49Gy). Due to small numbers $(n=10)$, patients receiving SBRT were excluded from this analysis.

\section{Results}

Baseline patient characteristics

A total of 535 patients with stage II NSCLC were referred to BC Cancer during the study period. Of these, 245 (46\%) received curative intent surgery, 132 (25\%) curative intent radiotherapy, and 158 (30\%) did not receive curative 
therapy. Baseline characteristics are presented in Table 1. In the entire population: median age $72,51 \%$ female, $36 \%$ adenocarcinoma, 60\% ECOG 0-1, 6\% never smokers, and $52 \%$ weight loss $<5 \%$ body weight. There were significant differences between cohorts with respect to median age, histology, ECOG PS, smoking status, and weight loss.

\section{Treatment}

Details of therapy employed for patients receiving curative and palliative intent treatment are presented in Table 2. There was a significant difference in the use of chemotherapy in the surgery and radiotherapy cohorts (54\% vs $26 \%, p<0.001)$. Among patients receiving non-curative therapy, 109 (69\%) received palliative radiotherapy.

\section{Overall and disease-free survival}

At the time of analysis, $426(80 \%)$ of patients had died. Median OS was $27.1 \mathrm{~m}$ (months) in the entire population. Median OS was significantly different between cohorts: $61.4 \mathrm{~m}$ surgery, $26.5 \mathrm{~m}$ CurRT, and $13.1 \mathrm{~m}$ noncurative therapy (Fig. 1a). Estimated 5-year survival rates were higher in the surgery cohort at 50.6\% (95\% confidence interval [CI] 44.2-57.0\%) compared to the CurRT cohort at $26.1 \%$ (95\% CI $18.3-33.9 \%$ ). Five-year OS was inferior in the cohort receiving non-curative therapy at $4.5 \%$ (95\% CI $1.3-7.7 \%)$.
Table 2 Therapy received

\begin{tabular}{lll}
\hline Surgery $(n=245)$ & & \\
\hline Surgical procedure & Sub-lobar resection & $94 \%$ \\
& Lobectomy & $20483 \%$ \\
& Pneumonectomy & $3213 \%$ \\
Chemotherapy & None & $11246 \%$ \\
& Adjuvant & $12651 \%$ \\
& Neoadjuvant & $73 \%$ \\
Curative Radiotherapy $(n=132)$ & & \\
RT dose & $\geq 66 G y$ & $1612 \%$ \\
& 60-66Gy & $4333 \%$ \\
& SBRT & $108 \%$ \\
Chemotherapy & 50-59Gy & $6348 \%$ \\
& None & $9874 \%$ \\
Non-curative treatment $(n=158)$ & & $3124 \%$ \\
Palliative radiotherapy & Concurrent & $32 \%$ \\
Bestemic treatment & & $10969 \%$ \\
Sapportive care & & $128 \%$ \\
& & $4428 \%$
\end{tabular}

Values are presented as $\mathrm{n}(\%)$

$R T$ radiation, SBRT stereotactic body radiation therapy

*7 patients received both palliative RT and systemic therapy

Table 1 Baseline characteristics of surgery and radiation cohorts

\begin{tabular}{|c|c|c|c|c|c|c|}
\hline & & $\begin{array}{l}\text { Surgery } \\
n=245\end{array}$ & $\begin{array}{l}\text { Curative RT } \\
n=132\end{array}$ & $\begin{array}{l}\text { Non-curative treatment } \\
n=158\end{array}$ & $p$-value & $\begin{array}{l}p \text {-value } \\
\text { Surg vs RT }\end{array}$ \\
\hline \multirow[t]{2}{*}{ Age } & Median & 67 & 73 & 78 & $<0.001$ & $<0.001$ \\
\hline & (range) & $43-86$ & $35-94$ & $55-93$ & & \\
\hline \multirow[t]{2}{*}{ Sex } & Female & 133 54\% & $6146 \%$ & $8051 \%$ & 0.322 & 0.135 \\
\hline & Male & $11246 \%$ & $7154 \%$ & $7849 \%$ & & \\
\hline \multirow[t]{3}{*}{ Histology } & Adenocarcinoma & 138 56\% & $3426 \%$ & $2013 \%$ & $<0.001$ & $<0.001$ \\
\hline & Squamous & $7631 \%$ & $4232 \%$ & $5635 \%$ & & \\
\hline & NOS/other & $3113 \%$ & $5642 \%$ & $8252 \%$ & & \\
\hline ECOG & $0-1$ & $17371 \%$ & $8766 \%$ & $5937 \%$ & $<0.001$ & 0.614 \\
\hline performance & $\geq 2$ & $6125 \%$ & $3930 \%$ & $9460 \%$ & & \\
\hline status & Unknown & $115 \%$ & $65 \%$ & $53 \%$ & & \\
\hline \multirow[t]{3}{*}{ Weight loss } & $\begin{array}{l}<5 \% \text { body weight } \\
5-10 \%\end{array}$ & $\begin{array}{l}14559 \% \\
3916 \%\end{array}$ & $\begin{array}{l}7355 \% \\
1612 \%\end{array}$ & $\begin{array}{l}6139 \% \\
2516 \%\end{array}$ & 0.001 & 0.122 \\
\hline & $>10 \%$ & $208 \%$ & $2116 \%$ & $2818 \%$ & & \\
\hline & Unknown & $4117 \%$ & $2217 \%$ & $4428 \%$ & & \\
\hline \multirow[t]{4}{*}{ Smoking } & Never & $208 \%$ & $32 \%$ & $117 \%$ & 0.046 & 0.053 \\
\hline & Former & $11346 \%$ & $7456 \%$ & $7447 \%$ & & \\
\hline & Current & $10945 \%$ & $5239 \%$ & $6541 \%$ & & \\
\hline & Unknown & $31 \%$ & $32 \%$ & $85 \%$ & & \\
\hline
\end{tabular}

Values are presented as $\mathrm{n}(\%)$ unless otherwise indicated

$R T$ radiation, ECOG Eastern Cooperative Oncology Group

Never smokers: less than 100 cigarettes over lifespan; former smokers: quit greater than 1 year ago; current smokers: actively smoking or quit less than 1 year ago 


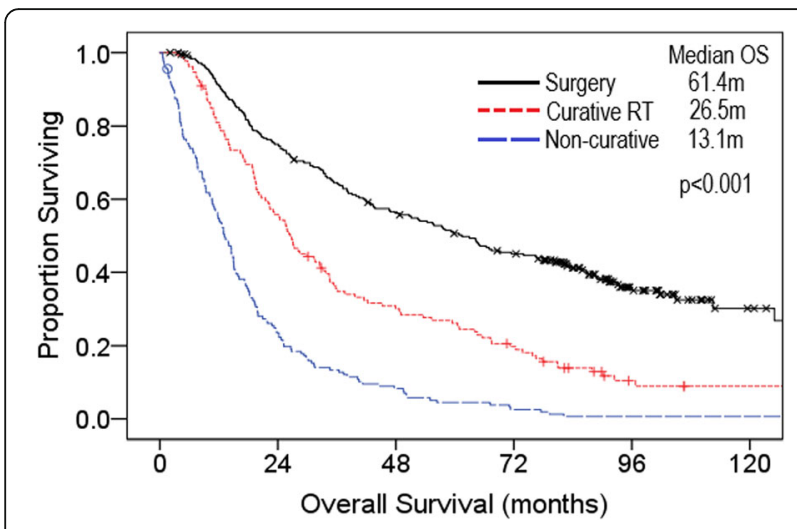

Fig. 1 Kaplan-Meier overall survival curves for surgery $(n=245)$, curative radiation ( $n=132)$, and non-curative treatment $(n=158)$ cohorts $m$, months; RT, radiotherapy

A total of 293 (78\%) of patients receiving curative intent therapy developed recurrent disease or died. Median DFS was $27.1 \mathrm{~m}$ in the overall population. There was improved DFS with surgery with median DFS $36.4 \mathrm{~m}$ for surgery and $19.6 \mathrm{~m}$ for CurRT. Estimated 5-year DFS was $41.3 \%$ (95\% CI $34.9-47.7 \%$ ) for surgery and $15.9 \%$ (95\% CI 9.3-22.5\%) for CurRT.

In the surgery cohort $172(70 \%)$ of patients had recurrent disease versus 121 (92\%) in the radiotherapy cohort.
There was a significant difference in the type of recurrence event: in the surgery cohort there was a higher proportion of local only recurrence ( $27 \%$ vs $19 \%)$, distant recurrence ( $46 \%$ vs $36 \%)$, and second primary ( $5 \%$ vs $1 \%$ ) $(p<0.001)$. In the radiotherapy cohort, more patients died without a prior documented recurrence event $(52 \%$ vs $20 \%)$. In the patients with recurrence, only a small fraction received subsequent systemic therapy: $27 \%$ the surgical and $19 \%$ in the radiotherapy cohort respectively.

\section{Univariate and multivariate analysis for OS}

In patients receiving curative intent therapy, younger age, ECOG PS 0-1, adenocarcinoma histology, lack of weight loss, and never smoking were associated with improved overall survival in univariate analysis (Table 3). Comparing treatment cohorts, curative therapy with radiation was inferior to surgery (HR 2.06). Age, sex, histology, ECOG PS, weight loss, smoking status, and treatment cohort were included in a multivariate model. In this model, the impact of ECOG PS, weight loss, and treatment cohort remained significant.

\section{Case-control analysis}

Per the specified criteria, a match was identified for 106 $(80 \%)$ of the patients receiving curative intent radiotherapy. Baseline characteristics among matched pairs: median

Table 3 Univariate analysis and multivariate model of factors associated with overall survival in patients receiving curative intent therapy. HR> 1.0 indicates increased risk of death

\begin{tabular}{|c|c|c|c|c|c|c|}
\hline & & \multicolumn{2}{|l|}{ UVA } & \multicolumn{3}{|l|}{ MVA } \\
\hline & & $\mathrm{HR}$ & $p$-value & $\mathrm{HR}$ & $95 \% \mathrm{Cl}$ & $p$-value \\
\hline \multirow[t]{2}{*}{ Group } & Surgery & Ref & $<0.001$ & Ref & & \\
\hline & Radiation & 2.062 & & 1.730 & $1.284-2.330$ & $<0.001$ \\
\hline Age & & 1.038 & $<0.001$ & 1.013 & $0.998-1.029$ & 0.094 \\
\hline \multirow[t]{2}{*}{ Sex } & Female & Ref & 0.354 & Ref & & \\
\hline & Male & 1.094 & & 0.979 & $0.757-1.267$ & 0.873 \\
\hline \multirow[t]{3}{*}{ Histology } & Adenocarcinoma & Ref & & Ref & & \\
\hline & Squamous & 1.571 & $<0.001$ & 1.041 & $0.761-1.423$ & 0.802 \\
\hline & NOS/other & 1.997 & $<0.001$ & 0.955 & $0.679-1.342$ & 0.791 \\
\hline \multirow[t]{2}{*}{ ECOG } & $0-1$ & Ref & $<0.001$ & Ref & & \\
\hline & $>=2$ & 2.156 & & 1.590 & $1.210-2.090$ & 0.001 \\
\hline \multirow[t]{4}{*}{ Weight loss } & $<5 \%$ & Ref & & Ref & & \\
\hline & $5-10 \%$ & 1.100 & 0.510 & 0.847 & $0.585-1.226$ & 0.378 \\
\hline & $>10 \%$ & 2.294 & $<0.001$ & 1.668 & $1.139-2.444$ & 0.009 \\
\hline & unk & 1.105 & 0.438 & 0.783 & $0.539-1.136$ & 0.197 \\
\hline \multirow[t]{3}{*}{ Smoking } & Never & Ref & & Ref & & \\
\hline & Former & 1.391 & 0.126 & 1.097 & $0.595-2.020$ & 0.767 \\
\hline & Current & 1.398 & 0.124 & 1.253 & $0.667-2.354$ & 0.484 \\
\hline \multirow[t]{2}{*}{ Chemotherapy } & No & Ref & $<0.001$ & Ref & & \\
\hline & Yes & 0.560 & & 0.707 & $0.524-0.954$ & 0.023 \\
\hline
\end{tabular}


age 71, 47\% female, 71\% ECOG PS 0-1, 57\% weight loss $<5$, and $44 \%$ current smokers. There was a higher proportion of patients with NOS histology in the radiotherapy cohort ( $45 \%$ vs $12 \%)$.

Median overall survival was $47.9 \mathrm{~m}$ in the entire matched cohort. Median OS remained superior in the surgery cohort at $101.6 \mathrm{~m}$ compared to $28.1 \mathrm{~m}$ in the CurRT cohort (Fig. 2). Five-year OS was estimated at $59 \%$ for surgery and $30 \%$ for CurRT.

\section{Optimizing RT}

Within the CurRT cohort, 34 (26\%) patients received concurrent or sequential chemotherapy (C/SRT), and 98 (74\%) of patients received RT alone. Patients receiving C/ SRT were younger (median age 66 vs 76) and had better ECOG PS (85\% PS $0-1$ vs $59 \%$ ) than patients receiving RT alone. Median OS was longer in the C/SRT group at $33.1 \mathrm{~m}$ compared to $23.2 \mathrm{~m}$ for RT alone (Fig. 3).

There was a significant association between median OS and RT dose, with superior survival seen in patients receiving $>=60 \mathrm{~Gy}$ at $32.6 \mathrm{~m}$, compared to $20.6 \mathrm{~m}$ for 50-59 Gy, and $14.5 \mathrm{~m}$ for 30-49 Gy (Fig. 4). Of the 63 patients receiving 50-59Gy, 48 (76\%) received 55-59Gy, mostly at a dosing and fractionation of $55 \mathrm{~Gy} / 20 \mathrm{fr}$. There was no significant survival difference between patients receiving 50-54Gy and 55-59Gy.

\section{Discussion}

In a large population-based study, we evaluated the landscape of treatment and outcomes in stage II NSCLC. Although considered standard of care, less than half of patients received surgical resection. Median overall survival was $27.1 \mathrm{~m}$ in the entire population and differed significantly based on the type of treatment received. Surgery achieved superior survival compared to radical

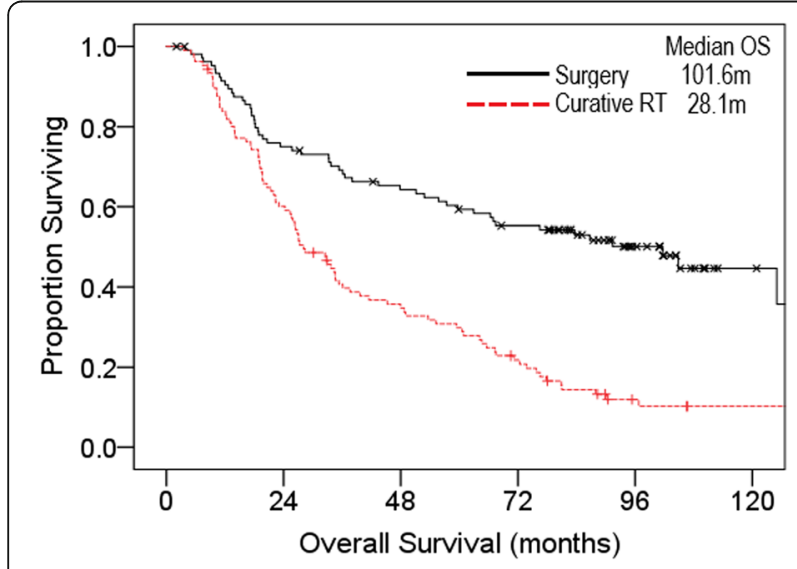

Fig. 2 Kaplan-Meier overall survival curves in the case-control population, comparing surgery $(n=106)$ matched by age $(+/-5$ years), sex, ECOG (0-1 or 2), and smoking status (never, former, current) to radiotherapy $(n=106) \mathrm{m}$, months; RT, radiotherapy

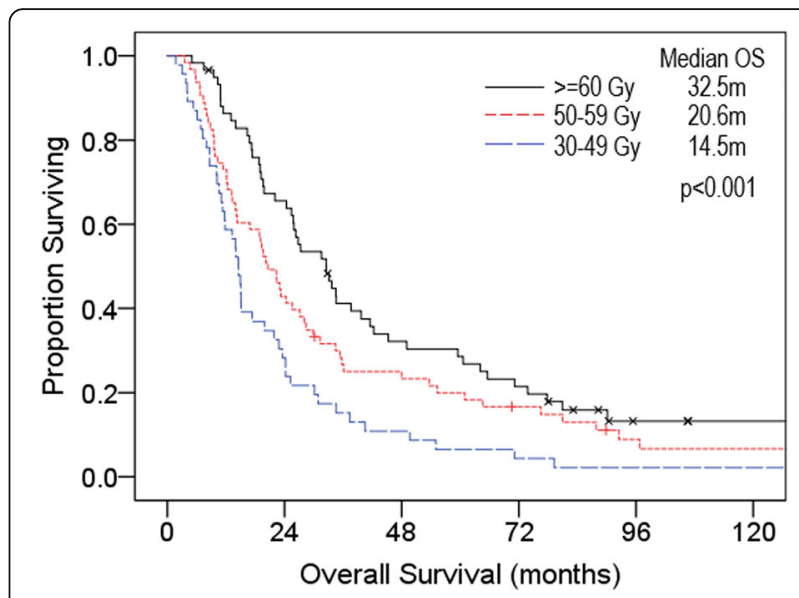

Fig. 3 Kaplan-Meier overall survival curve in the curative RT cohort comparing concurrent/sequential chemoradiation $(n=34)$ to curative RT alone $(n=98) \mathrm{m}$, months; RT, radiotherapy

radiotherapy. Although this may be in part due to an imbalance in prognostic factors, the difference persisted in both a multivariate analysis and case-matched analysis.

The median overall survival in the surgery cohort was $61.4 \mathrm{~m}$, and the 5 -year OS was $51 \%$. This is similar to the surgical series of the IASLC staging project for AJCC Version 7. It is sobering that despite surgical management, only half of patients are cured with the best modality available. Adjuvant chemotherapy has been shown to improve survival in stage II NSCLC [8-11], however only half of the patients in our study received adjuvant chemotherapy. This is similar to other Canadian populationbased studies and may reflect a variety of factors including a lack of referral to medical oncology, patient decision, and comorbidities [20,21]. Optimizing uptake of adjuvant chemotherapy is therefore a means to improve survival in stage II NSCLC on a population level. Exploration of alternative systemic options such as neoadjuvant therapy,

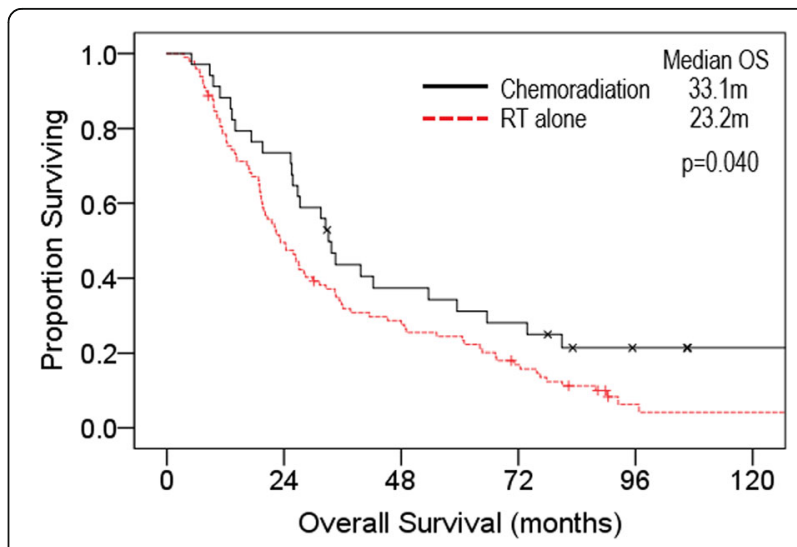

Fig. 4 Kaplan-Meier overall survival curves of all patients treated with radiotherapy comparing $\geq 60 \mathrm{~Gy}(n=59), 50-59 \mathrm{~Gy}(n=63)$ and high-dose palliative radiotherapy 30-49 Gy $(n=46)$ 
immunotherapy, or targeted treatments in suitable populations are under study and may offer more patient tailored approaches for curative treatment [22-27].

A significant proportion of patients received curative intent radiotherapy due to medical inoperability or patient decision. The survival outcomes in our study were similar to previously published reports $[17,28-30]$, although inferior to surgery with 5 -year OS being $26 \%$. In both a multivariate model and a case-matched analysis, the performance of surgery remained superior to curative intent radiotherapy. There were a high proportion of patients in the radiotherapy cohort who died without a previously documented recurrence event. Many of these deaths are assumed to be from lung cancer, however the exact cause of death was not available. There may be a higher death rate from non-malignant causes from competing mortality due to comorbid conditions that render a patient inoperable in the first place. The radiotherapy cohort had a numerically lower number of patients with a local only recurrence, however this does not necessarily reflect better local control. Patients with distant metastases may have also had local relapse, and the high proportion of patients who died without a documented recurrence event may have died before a local relapse could develop or be confirmed.

Our findings of improved outcomes with surgery in stage II NSCLC mirror other retrospective studies in stage I disease comparing stereotactic body radiation therapy (SBRT) versus surgical resection. In a metaanalysis of over 150, 000 unmatched SBRT and surgical patients and over 17,000 matched patients, the survival was superior with surgery in both unmatched and matched populations albeit with a smaller benefit in the matched group [31]. This finding suggests that the improved outcomes must be, in part, related to differences in baseline patient and disease characteristics. In contrast, the combined analysis of prospective STARS and ROSEL studies of SBRT versus lobectomy for operable stage I NSCLC, the estimated OS at 3 years was $95 \%$ with SBRT and $79 \%$ in surgery [32]. The caveat of this analysis related to the small numbers $(n=58)$ and need to pool the data due to accrual issues. This provides some insight into the possible contribution of inoperability to outcomes when comparing groups in the retrospective studies. While these studies focus on SBRT and an earlier stage of NSCLC, it helps to highlight the contribution of baseline patient and disease characteristics to outcomes rather than the modality of therapy.

There is clear room for improvement in the outcomes for inoperable patients treated with curative intent radiotherapy. Prior studies have suggested that the addition of concurrent chemotherapy may improve survival [28], similar to what has been shown for stage III NSCLC [33]. However, the use of concurrent chemotherapy was low in our population. This may be due to both a lack of prospective evidence to support concurrent treatment, and the unique nature of the inoperable population, as many factors that make patients poor operative candidates would also make them poor candidates for chemotherapy.

Optimizing radiotherapy dose may be another means to improve outcomes in this population. Guidelines for locally advanced NSCLC suggest that a dose of $60 \mathrm{~Gy}$ should be used when treating with definitive radiotherapy, but it is not clear if this can be extrapolated to stage II disease [34]. Prior retrospective studies have defined curative radiotherapy for early stage NSCLC as a minimum dose of 50Gy [29,30]. Our study showed superior outcomes in patients treated with $>60$ Gy compared to those treated with lower doses of potentially curative radiotherapy, which is consistent with other retrospective studies [17]. However, doses of 50-59 Gy did portend a survival benefit over moderate-high dose palliative radiotherapy and represents a potentially curative, albeit inferior modality, with a 5 -year overall survival of $21 \%$. Most patients within this group received $55 \mathrm{~Gy} / 20 \mathrm{fr}$, which corresponds to an equieffective dose delivered in 2 fractions (EDQ2) of 58.2Gy. Therefore, one might expect similar effectiveness to patients receiving $\geq 60$ Gy which was not seen in our study. Selection bias may play a role, as less fit patients may be selected for the shorter treatment course offered by a $55 \mathrm{~Gy} / 20 \mathrm{fr}$ dosing schedule. There was no survival difference seen between 50-54Gy and 55-59Gy, though this analysis was limited by small patient numbers.

Adjuvant immunotherapy post-chemoradiotherapy with durvalumab has shown significant improvements in survival in patients with stage III NSCLC $[35,36]$. It is unknown if these benefits can be extrapolated to the population receiving radical radiotherapy or chemoradiotherapy for stage II disease. The current PACIFIC4 trial is evaluating adjuvant durvalumab after SBRT and includes node negative stage II patients (T3 N0), which may help inform this issue [37]. However, there will still be uncertainty regarding the potential role of adjuvant immunotherapy in inoperable stage II patients who are either node positive or have tumors not amenable to SBRT.

We confirmed the prognostic impact of age, histology, weight loss, and ECOG performance status. In multivariate analysis, treatment cohort and ECOG PS were the strongest predictors of survival, which is consistent with prior studies reporting ECOG PS as the most robust prognostic indicator in NSCLC [38]. There was an increase in proportion of NOS histology among the non-surgical cohorts, likely due to less tissue being available for analysis.

Although our study included patients defined as stage II disease by the AJCC 7th edition, there were only minor changes made to stage II disease in the AJCC 8th edition. Some patients included in our study, such as those with tumors greater than $7 \mathrm{~cm}$, or greater than 5 
cm with N1 involvement, would now be classified as having stage III disease. Therefore, the prognosis seen in our study may be slightly worse than that for a population of stage II patients defined by the AJCC 8th edition.

Our study is limited by its retrospective nature, however it is unlikely surgery and radiotherapy in this setting will ever be successfully compared in a prospective trial. In addition, comorbidity data were not available and data for known driver mutations were limited, as EGFR testing began at our institution in 2010, and ALK in 2014. The strengths include the large real-world population and the detailed information available on both baseline characteristics and treatment details. We attempted to account for the imbalance in prognostic factors between treatment cohorts in both a multivariate model and a case-matched analysis. We were able to describe the outcomes of a large group of patients treated with curative intent radiotherapy, where there is currently very limited data to guide treatment choices.

\section{Conclusion}

There is a large proportion of patients with stage II NSCLC who are unable to receive standard of care surgical resection. Although inferior to surgery, radical radiotherapy remains a potentially curative option in inoperable patients. Optimizing radiotherapy dose and the use of concurrent chemotherapy may be strategies to improve outcomes in this population. With lung cancer screening programs leading to a migration to earlier stage at diagnosis, it will be important to focus future research efforts on this growing patient population.

\footnotetext{
Abbreviations

AJCC: American Joint Committee on Cancer; ALK: Anaplastic lymphoma kinase; BC: British Columbia; C/SRT: Concurrent or sequential chemotherapy; CurRT: Curative intent radiation; DFS: Disease-free survival; ECOG: Eastern cooperative oncology group; EGFR: Epidermal growth factor receptor; IASLC: International association for the study of lung cancer; NOS: Not otherwise specified; NSCLC: Non-small cell lung cancer; OS: Overall survival; PS: Performance status; RT: Radiation therapy; SBRT: Stereotactic body radiation therapy
}

\section{Acknowledgements}

Paul Mak, Surveillance and Outcomes Analyst, for assistance with the OaSIS database.

The Eleni Skalbania Endowment for Lung Cancer Research and the BC Cancer Foundation for supporting OaSIS

\section{Authors' contributions}

SM collected and analyzed patient data, and was the primary author of the manuscript. BL collected a significant amount of patient data, JW was involved in the design of the work and interpretation of data, $\mathrm{CH}$ was involved in design of the work, data analysis, and interpretation of data. All authors read and reviewed the final manuscript.

\section{Funding}

This research did not receive any specific grant from funding agencies in the public, commercial, or not-for-profit sectors.

\section{Availability of data and materials}

The datasets generated and/or analysed during the current study are not publicly available due lack of approval from Research Ethics Board, but may be available from the corresponding author on reasonable request.

Ethics approval and consent to participate

This work received approval from the University of British Columbia - British Columbia Cancer Agency Research Ethics Board (REB\# H15-02509)

\section{Consent for publication}

Not applicable

\section{Competing interests}

The authors declare that they have no completing interests

\section{Author details}

${ }^{1}$ University of British Columbia, Vancouver, BC V6T 1Z4, Canada. 'Department of Medical Oncology, BC Cancer 600 W 10th Avenue Vancouver, Vancouver, BC V5Z 4E6, Canada. '3 Department of Radiation Oncology, BC Cancer 600 W 10th Avenue Vancouver, Vancouver, BC V5Z 4E6, Canada.

Received: 1 November 2019 Accepted: 14 January 2020

Published online: 30 January 2020

\section{References}

1. World cancer report 2014. Geneva, Switzerland: International Agency for Research on Cancer. 2014

2. Canadian Cancer Statistics Advisory Committee. Canadian cancer statistics 2018. Canadian Cancer Society 2018.

3. Aberle DR, Adams AM, Berg CD, et al. Reduced lung-cancer mortality with low-dose computed tomographic screening. N Engl J Med. 2011;365(5): 395-409.

4. De Koning HJ, Van Der Aalst, Carlijn M, ten Haaf K, Oudkerk M. Effects of volume CT lung cancer screening: mortality results of the NELSON randomised-controlled population based trial. Oral presentation at: world conference on lung Cancer; September 2018; Toronto, ON

5. Goldstraw P, Chansky K, Crowley J, et al. The IASLC lung cancer staging project: proposals for revision of the TNM stage groupings in the forthcoming (eighth) edition of the TNM classification for lung cancer. J Thorac Oncol. 2016;11(1):39-51.

6. Ettinger DS, Akerley W, Borghaei $\mathrm{H}$, et al. Non-Small cell lung cancer. Journal of the National Comprehensive Cancer Network: JNCCN. 2012; 10(10):1236-71.

7. Ramnath N, Dilling TJ, Harris $L$, et al. Treatment of stage I and II non-small cell lung cancer: diagnosis and management of lung cancer, 3rd ed: American college of chest physicians evidence-based clinical practice guidelines. Chest. 2013;143(5 Suppl):e314S.

8. Arriagada R, Bergman B, Dunant A. Cisplatin-based adjuvant chemotherapy in patients with completed resected non-small-cell lung cancer. N Engl J Med. 2004;350:351-60.

9. Winton $T$, Livingston $R$, Johnson $D$, et al. Vinorelbine plus cisplatin vs. observation in resected non-small-cell lung cancer. N Engl J Med. 2005; 352(25):2589-97.

10. Pignon J-P, Tribodet H, Scagliotti GV, et al. Lung adjuvant cisplatin evaluation: a pooled analysis by the LACE collaborative group. J Clin Oncol. 2008;26(21):3552-9.

11. Douillard JY, Rosell R, De Lena M, Carpagnano F, Ramlau R, Gonzales-Larriba $J$ L. Adjuvant vinorelbine plus cisplatin versus observation in patients with completely resected stage IB-IIIA non-small-cell lung cancer (adjuvant navelbine international trialist association [ANITA]): a randomized controlled trial. Lancet Oncol. 2006;7(9):719-27.

12. Sineshaw HM, Wu X, Flanders WD, Osarogiagbon RU, Jemal A. Variations in receipt of curative-intent surgery for early-stage non-small cell lung cancer (NSCLC) by state. J Thorac Oncol. 2016;11(6):880-9.

13. Haque W, Szeja S, Tann A, Kalra S, Teh BS. Changes in treatment patterns and overall survival in patients with early-stage non-small cell lung cancer in the United States after the incorporation of stereotactic ablative radiation therapy: a population-based analysis. Am J Clin Oncol. 2018;41(3):259.

14. Haasbeek CJA, Palma DA, Visser O, Lagerwaard FJ, Slotman BJ, Senan S. Early-stage lung cancer in elderly patients: a population-based study of 
changes in treatment patterns and survival in the Netherlands. Ann Oncol. 2012;23(10):2743-7.

15. Valle LF, Jagsi R, Bobiak SN, et al. Variation in definitive therapy for localized non-small cell lung cancer among national comprehensive cancer network institutions. Int J Radiat Oncol Biol Phys. 2016;94(2):360-7.

16. Liu HW, Gabos Z, Ghosh S, Roberts B, Lau H, Kerba M. Outcomes in stage non-small cell lung cancer following the introduction of stereotactic body radiotherapy in Alberta - a population-based study. Radiother Oncol. 2015; 117(1):71-6

17. Sampath S, Hall M, Schultheiss TE. Definitive chemotherapy and radiotherapy in patients with stage II non-small cell lung cancer: a population-based outcomes study. Lung Cancer. 2015;90(1):61-4.

18. San José S, Arnaiz MD, Lucas A, et al. Radiation therapy alone in elderly with early stage non-small cell lung cancer. Lung Cancer. 2006;52(2):149-54.

19. Joo JH, Song SY, Kim SS, et al. Definitive radiotherapy alone over $60 \mathrm{~Gy}$ for patients unfit for combined treatment to stage II-III non-small cell lung cancer: Retrospective analysis. Radiat Oncol (London, England). 2015;10(250):1-8.

20. Younis T, Al-Fayea T, Virik K, Morzycki W, Saint-Jacques N. Adjuvant chemotherapy uptake in non-small cell lung cancer. J Thorac Oncol. 2008; 3(11):1272-8.

21. Kassam F, Shepherd FA, Johnston M, et al. Referral patterns for adjuvant chemotherapy in patients with completely resected non-small cell lung cancer. J Thorac Oncol. 2007;2(1):39-43.

22. AstraZeneca. AZD9291 versus placebo in patients with stage IB-IIIA nonsmall cell lung carcinoma, following complete tumour resection with or without adjuvant chemotherapy. (ADAURA). https:/clinicaltrials.gov/ct2/ show/NCT02511106. Updated 2015. Accessed 18 August 2019.

23. AstraZeneca. A study of neoadjuvant/adjuvant durvalumab for the treatment of patients with resectable non-small cell lung cancer. https:// clinicaltrials.gov/ct2/show/NCT03800134. Updated 2019. Accessed 18 August 2019.

24. Hoffmann-La Roche. A study comparing adjuvant alectinib versus adjuvant platinum-based chemotherapy in patients with ALK positive non-small cell lung cancer. https:/clinicaltrials.gov/ct2/show/NCT03456076. Updated 2018.

25. Hoffmann-La Roche. A study of neoadjuvant atezolizumab plus chemotherapy versus placebo plus chemotherapy in patients with resectable stage II, III, or select IIIB non-small cell lung cancer (IMpower030). https://clinicaltrials.gov/ct2/ show/NCT03456063. Updated 2018.

26. Merck Sharp \& Dohme Corp. Efficacy and safety of pembrolizumab (MK3475) with platinum doublet chemotherapy as neoadjuvant/adjuvant therapy for participants with resectable stage II, IIIA, and resectable IIIB (T34N2) non-small cell lung cancer (MK-3475-671/KEYNOTE-671). https:// clinicaltrials.gov/ct2/show/NCT03425643. Updated 2018.

27. National Cancer Institute. Nivolumab after surgery and chemotherapy in treating patients with stage IB-IIIA non-small cell lung cancer (an ALCHEMIST treatment trial) (ANVIL). https://clinicaltrials.gov/ct2/show/ NCT02595944. Updated 2015. Accessed 18 August 2019.

28. Dudani S, Leighl NB, Ho C, Pantarotto J, Zhu X, Zhang T, Wheatley-Price P. Approach to the non-operative management of patients with stage II nonsmall cell lung cancer (NSCLC): a survey of Canadian medical and radiation oncologists. Lung Cancer. 2016;94:74-80.

29. Smith SL, Palma D, Parhar T, Alexander CS, Wai ES. Inoperable early stage non-small cell lung cancer: comorbidity, patterns of care and survival. Lung Cancer. 2011;72(1):39-44.

30. Nguyen AD, Wong W, Beydoun N, Mohan S, Shafiq J, Vinod SK. Radiotherapy patterns of care for stage I and II non-small cell lung cancer in Sydney, Australia. J Med Imaging Radiat Oncol. 2019;63(1):131-41.

31. Cao C, Wang D, Chung C, et al. A systematic review and meta-analysis of stereotactic body radiation therapy versus surgery for patients with nonsmall cell lung cancer. J Thorac Cardiovasc Surg. 2019;157(1):362-73.

32. Chang JY, Senan S, Paul MA, et al. Stereotactic ablative radiotherapy versus lobectomy for operable stage I non-small-cell lung cancer: a pooled analysis of two randomised trials. Lancet Oncol. 2015;16:630-7.

33. Schaake-Koning C, van den Bogaert W, Dalesio O, et al. Effects of concomitant cisplatin and radiotherapy on inoperable non-small-cell lung cancer. N Engl J Med. 1992;326:524-30.

34. Bezjak A, Temin S, Franklin G, et al. Definitive and adjuvant radiotherapy in locally advanced non-small-cell lung cancer: American Society of Clinical Oncology clinical practice guideline endorsement of the American Society for Radiation Oncology evidence-based clinical practice guideline. J Clin Oncol. 2015;33(18):2100-5.
35. Antonia SJ, Villegas A, Vicente DD, et al. Overall survival with Durvalumab after chemoradiotherapy in stage III NSCLC. N Engl J Med. 2018;379:2342-50.

36. Antonia SJ, Villegas A, Daniel D, et al. Durvalumab after chemoradiotherapy in stage III non-small-cell lung cancer. N Engl J Med. 2017;377(20):1919-29.

37. AstraZeneca. Durvalumab vs placebo following stereotactic body radiation therapy in early stage non-small cell lung cancer patients (PACIFIC-4). https://clinicaltrials.gov/ct2/show/NCT03833154. Updated 2019. Accessed 18 August 2019.

38. Cuyún Carter G, Barrett AM, Kaye JA, Liepa AM, Winfree KB, John WJ. A comprehensive review of nongenetic prognostic and predictive factors influencing the heterogeneity of outcomes in advanced non-small-cell lung cancer. Cancer Manag Res. 2014;6:437-49.

\section{Publisher's Note}

Springer Nature remains neutral with regard to jurisdictional claims in published maps and institutional affiliations.
Ready to submit your research? Choose BMC and benefit from:

- fast, convenient online submission

- thorough peer review by experienced researchers in your field

- rapid publication on acceptance

- support for research data, including large and complex data types

- gold Open Access which fosters wider collaboration and increased citations

- maximum visibility for your research: over $100 \mathrm{M}$ website views per year

At BMC, research is always in progress.

Learn more biomedcentral.com/submissions 